\title{
Onirossignos deleuzianos no videoclipe Hyperballad: interfaces cinematográficas
}

\section{Deleuzian "onirosigns" in the videoclip Hyperballad: cinematic interfaces}

\section{Denise AZevedo Duarte GuimarÃes}

Doutora em Estudos Literários pela UFPR. Docente do Mestrado e Doutorado em Comunicação e Linguagens/UTP.

Coordenadora da Linha de Estudos de Cinema e Audiovisual do PPGCOM/UTP.

<denise.guimaraes@utp.br>

\section{RESUMO}

$\mathrm{O}$ artigo analisa o videoclipe Hyperballad, roteirizado e apresentado por Björk, com a direção de Michel Gondry, com ênfase nas interlocuções tecnoestéticas entre produtos audiovisuais e o cinema. $\mathrm{O}$ texto também indaga em que medida a obra anuncia características do cinéma du look uma tendência do cinema francês, na qual o diretor se insere. A noção sobre imagem-tempo de Deleuze, na instância sígnica da imagem-sonho, é a principal base teórica; e, desse modo, o diálogo com Peirce é fundamental para entender os onirossignos deleuzianos no videoclipe. Finalmente, a fenomenologia dos sonhos de Bachelard é utilizada, para interpretar as modulações espaço-temporais da narrativa onírica na tela.

Palavras-chave: Videoclipe. Cinema. Narrativa onírica.

\section{ABSTRACT}

This paper analyses the videoclip Hyperballad, scripted and presented by Björk, and directed by Michel Gondry, with emphasis on the techno-aesthetic interlocutions between audiovisual products and cinema. The text also asks to which extent the work announces characteristics of the cinéma du look - a tendency of French cinema, in which the director is integrated. The Deleuze's notion of time-image, in the signic instance of dream-image, is the main theoretical basis; thus, the dialogue with Peirce is crucial to understand the Deleuzian "onirosigns" in the videoclip. Finally, the Bachelard's phenomenology of dreams is used, in order to interpret the space-temporal modulations of oneiric narrative on the screen.

Keywords: Videoclip. Cinema. Oneiric narrative. 


\section{Considerações iniciais}

o possibilitar a dissolução da imagem realista tradicional e o distanciamento do 1 padrão fotográfico e cinematográfico, a informática redimensionou a linguagem da televisão, no final da década de 1970. Surgiram, na época, as vinhetas de abertura dos programas e os comerciais sofisticados, produzidos com as novas tecnologias. Uma das novidades mais impactantes que a TV trouxe foi o videoclipe, escolhido como tema deste artigo, justamente por revelar-se como um meio de expressão audiovisual pleno de potencialidades tecnoestéticas.

Inicialmente, a música era apresentada na televisão de forma simples e direta: geralmente espetáculos gravados ao vivo ou em estúdio. Algumas vezes utilizavam-se sequências filmadas para "ilustrar" um sucesso musical. O videoclipe popularizouse, em grande parte devido à ação da MTV, que institucionalizou o formato, como obra que integra, de forma livre e criativa, o som e as imagens em movimento, num processo narrativo ligado às letras das canções. Seu prestígio cresceu com a adesão de videoartistas e de cineastas, tornando-se um gênero televisual com traços estilísticos específicos.

Na cena atual, graças às tecnologias digitais, a linguagem da televisão passou a ter acesso a processos híbridos, capazes de efetuar efeitos especiais e jogos inventivos com formas, cores, sons e movimento; o que permitiu ao videoclipe expandir suas experiências, num novo timing adequado a todos os ritmos.

Neste artigo, que é parte de uma pesquisa mais ampla sobre o tema, pretendo abordar a signagem do videoclipe, com ênfase nas interlocuções tecnoestéticas entre os produtos audiovisuais e o cinema. Para tanto, selecionei como objeto empírico de investigação o videoclipe Hyperballad ${ }^{1}$ roteirizado e protagonizado pela cantora Björk e dirigido por Michel Gondry, pois pretendo nele investigar as marcas estéticas peculiares do cineasta, que se evidenciam em seus filmes mais recentes. A escolha de 
um videoclipe de 1996 é justificada pela intenção de indagar, em que medida nele também se anunciam os traços do cinéma $d u$ look ${ }^{2}$ - tendência relevante do cinema francês, na qual Gondry se insere.

Meu aporte teórico fundamental é o conceito deleuziano da imagem-tempo, com ênfase na sua primeira instância sígnica, a imagem-sonho. $\mathrm{O}$ diálogo com Peirce faz-se relevante, pois o filósofo francês, com seu conceito de cinema do tempo, efetua uma releitura da semiótica peirciana. Deleuze afirma que a imagem-sonho não é uma metáfora, mas sim uma série de anamorfoses que traçam um circuito muito grande e apresentam uma afinidade natural com as vanguardas históricas do início do século passado. Reside aí uma das razões da escolha de uma obra de Gondry, conhecido por sua obsessão pelos estados alterados de consciência, tal como os surrealistas, e por seus diálogos com as artes plásticas. No clipe em questão, as subversões cronotópicas viabilizam as condições de existência dos onirossignos deleuzianos. Nesse sentido, os estudos fenomenológicos sobre o sonho efetuados por Bachelard, também leitor de Bergson como Deleuze, mostram-se molduras conceituais pertinentes. Finalmente, as trocas sígnicas entre a TV e o cinema são abordadas com aporte em teorias comunicacionais, estéticas e semióticas.

\section{A signagem videoclípica e as estratégias miméticas}

No transcorrer do século $X X$, o conceito de representação enfrenta várias crises e os signos, que passam a operar de forma dialética em relação ao objeto representado, chegam a exacerbar a subversão do conceito de mimesis. Nesse sentido, distanciando-se da linguagem do cinema clássico, que lhe serviu de modelo nos primeiros instantes, a televisão ganha determinada autonomia das imagens. No caso específico dos videoclipes mais inventivos, é possível neles identificar a proposta mimética que Xavier identifica ao cinema moderno. 
O discurso cinematográfico não deve imitar o verossímil (denominador real), tal como a decupagem clássica. Ele deve imitar a articulação dos sonhos, a lógica de uma experiência que é 'o preenchimento do desejo' por excelência. [...] Para tal, ele está melhor equipado do que qualquer outra modalidade de instrumento à disposição do poeta: o seu material (imagens visuais e sonoras) apresenta exclusiva afinida e com o material trabalhado pelo insconsciente (tal como entendido por Freud)."

(Xavier, 2008, p. 114)

A referência feita pelo autor à "articulação dos sonhos" é importante para a compreensão, não só do videoclipe de Gondry, mas também de muitos outros produtos audiovisuais que exploram a atmosfera onírica e que se associam às propostas surrealistas - ligadas ao que Freud considera como um desejo de subversão da realidade, afirmado na experiência do sonho. Trata-se de obras também associadas à pintura cubista, à videoarte e ao chamado cinema de poesia, no que diz respeito à tentativa de configuração de um relevo semiótico estético específico.

Minha a proposta é efetuar algumas reflexões sobre os videoclipes, que não deixam de ser uma forma de divulgação audiovisual dos produtos musicais, como dizia Pignatari, com sua "signagem" particularmente delineada, de modo a diferenciar-se do cinema. $\mathrm{O}$ neologismo foi criado pelo poeta e semioticista para se referir aos fenômenos não verbais. 
[...] o cinema mudo continua cinema; a televisão, porém, já nasceu sonora (quando muda, tende ela a reverter ao cinema, como pode ser observado na videoarte). Somem-se a isso a tela pequena e a compressão tempórica da imagem televisual e teremos os delineamentos principais de sua signagem."

(Pignatari, 1984, p. 16 - grifo meu)

Devido às peculiaridades do meio, que lhes confere plasticidade háptica e tátil, as signagens do vídeo e da televisão estruturam-se em diversos níveis de significação, variando, da obviedade dos jargões e dos clichês, à imponderabilidade ou ao estranhamento das propostas com ambições estéticas.

É importante considerar, na dinâmica da tela, as configurações presentes no âmbito do videoclipe que são oriundas das trocas intersemióticas entre os signos musicais e imagéticos, e que reverberam cineticamente as expressões verbais da letra da canção. A presente abordagem, contudo, não privilegia a dimensão verbal nem a sonora, pois procuro ater-me aos elementos visuais como princípios conceituais e operativos da signagem do videoclipe analisado, com ênfase no conceito deleuziano de imagem-tempo.

Ao concentrar a abordagem na rapidez e fugacidade das imagens cinéticas e nos apelos sensoriais, entre outros o interesse é flagrar aqueles efeitos considerados por Couchot como um "efeito singular de jubilação sensorial".

A arte produz, sem o que ela não é arte, um efeito singular de jubilação sensorial, de transe perceptivo, próprio às formas sensíveis que ela coloca em obras sejam elas realistas, abstratas, geométricas ou conceituais, uma vez que este transe pode nascer tanto de uma forma material quanto de uma forma imaterial e sem o qual não poderia captar, nem reter o olhar, a escuta, a atenção."

(Couchot, 2003, p. 311) 
Neste artigo, portanto, o videoclipe é entendido como uma espécie de jogo significante que atua no terreno das relações e significações complexas - o que propiciaria sua associação ao campo das poéticas tecnológicas, já devidamente incorporadas ao imaginário midiático contemporâneo.

\section{A tripla reversão}

Ao debruçar-se sobre Bergson e Peirce, no livro A Imagem-tempo, publicado originalmente em 1985, Deleuze considera que a imagem do denominado cinema moderno é a imagem-tempo; uma imagem que pode ser considerada virtual (que não se opõe ao real, no pensamento deleuziano), em contraposição à atualidade da "imagem-movimento" que caracteriza o chamado cinema clássico.

O filósofo define o que denomina de tripla reversão, ou seja, um para além do movimento nas telas, e que se efetiva em três instâncias imagéticas correspondentes: as três instâncias da imagem-tempo: imagem-sonho, imagem-lembrança e imagem-cristal.

Para Deleuze, a imagem-tempo está livre dos vínculos sensório-motores, ou seja, ela consiste em apresentações diretas no tempo, oriundas de uma brecha do movimento que faz aparecer o tempo, tornando-o visível. "[...] a imagem ótica e sonora pura, seus opsignos e sonsignos, ligam-se diretamente a uma imagem-tempo que sub-ordenou o movimento" (Deleuze, 2007, p. 33).

Minha abordagem concentra-se na primeira instância da imagem-tempo: a imagemsonho, composta por signos que se manifestam em diversos estados alterados de consciência ou durante o sono.

Ao problematizar um discurso sonhador sobre o sonho, considerado como algo para fazer pensar sobre a possibilidade do impossível, Derrida, em sua releitura de Freud (1967), pontua que: se não inexistente, pelo menos, não é clara a fronteira entre o espaço não fonético da escritura e "o espaço do palco do sonho". 
Não é, portanto, de surpreender que Freud, para sugerir a estranheza das relações lógico-temporais no sonho, recorra constantemente à escritura, à sinopse espacial do pictograma, da charada, do hieróglifo, da escrita nãofonética em geral. Sinopse e não estase: cena e não quadro. O laconismo, o lapidar do sonho não é a presença impassível dos signos petrificados."

(Derrida, 1971, p. 208)

Levando em conta que a obra de Deleuze sobre as três instâncias da imagem-tempo, que incluem a imagem-sonho, é publicada em 1985, tem-se duas décadas e todo um repertório pós-estruturalista a ser considerado; o que, a meu ver, permite a Deleuze refletir sobre os conceitos vigentes sobre as imagens oníricas e questionar as relações lógico-temporais no sonho, de modo a conceber seus onirossignos, como uma tentativa de ir além da faneroscopia peirciana.

[...] O signo e a imagem invertiam, portanto, sua relação, pois o signo já não supunha a imagem-movimento como matéria que ele representava sob suas formas especificadas; mas se punha a apresentar a outra imagem, da qual ele próprio ia especificar a matéria e constituir as formas, de signo em signo."

(Deleuze, 2007, p. 48. grifos meus)

Por outro lado, não se pode ignorar que Peirce também problematiza a questão da representação, ao assinalar que a sensação do firtness, consistindo apenas em 
uma impressão de certa espécie que "[...] é determinada por um poder inexplicável, oculto; e, nessa medida, não é representação, mas apenas a qualidade material de uma representação"(Peirce, 1983, p. 76).

O exposto permite-me associar os opsignos deleuzianos - como signos que não "representam" nada - ao conceito peirciano do qualis ou manifestação qualitativa do fenômeno. Sendo uma qualidade pura de sensações, uma espécie de feeling ou mera aparência segundo Peirce, o qualis decorre do entendimento semiótico de que a primeira condição ontológica de investigação fenomenológica é a primeiridade.

A ideia do Primeiro predomina nas ideias de novidade, vida, liberdade. Livre é o que não tem outro atrás de si determinando duas ações; mas assim aparece a ideia de outro, pela negação da alteridade; ela está presente para que se possa falar que a Primeiridade é predominante."

(Peirce, 1983, p. 88)

Minhas reflexões permitem-me entender que tanto Deleuze quanto Peirce referem-se a determinados tipos de signos susceptíveis a forças que afetam as formas habituais de representação; ou seja, ambos concebem agenciamentos sígnicos que correspondem a um desligamento do espaço, para alcançar a pura vibração das qualidades evanescentes.

Traço aqui este rápido esboço da problematização do diálogo possível e necessário entre os dois autores no que diz respeito à representação, mas que não é aprofundada neste artigo, porque as classsificações sígnicas, ora expostas sucintamente, destinam-se apenas à análise do presente objeto de estudo. 
No videoclipe Hyperballad, é relevante observar como tais signos visuais metamorfoseiam-se quanto à velocidade, instantaneidade e simultaneidade, propiciando uma temporalidade desconhecida do olhar e que pode ser identificada à dimensão onírica.

Meu raciocínio concentra-se no que concerne à primeira subdivisão conceitual da imagem-tempo - a imagem-sonho - que é caracterizada por Deleuze como um devir ao infinito, por uma qualidade no presente, livre de correlações ou determinações. Tais estratégias miméticas são facilmente identificáveis no videoclipe selecionado para análise, no qual a câmera torna-se questionadora e provocante. Tal efeito enfatiza a indiscernibilidade entre o subjetivo e o objetivo, como se percebe na narrativa audiovisual em questão. Para o filósofo,

[...] as situações óticas e sonoras puras podem ter dois pólos, objetivo e subjetivo, real e imaginário, físico e mental. Mas elas dão lugar a opsignos e sonsignos, que estão sempre fazendo com que os polos se comuniquem, e num sentido ou noutro asseguram as passagens $e$ as conversões, tendendo para um ponto de indiscernibilidade (e não de confusão)."

(Deleuze, 2007, p. 18)

Com a escolha de um videoclipe de tema onírico, o intento é, portanto, enfatizar as categorias sígnicas deleuzianas que possam ser considerados similares aos procedimentos inaugurados pelo cinema moderno. Entendo ser pertinente diferenciar as imagens do clipe dirigido por Michel Gondry das imagens-movimento do cinema 
dito clássico. Nesse sentido, as estratégias visuais e cinéticas identificadas na obra poderiam ser relacionadas ao "desfoque" _ procedimento que Deleuze identifica ao cinema da perambulação, no qual, como sonâmbulo, o personagem registra, mas não reage. "Personagens, envolvidas em situações óticas e sonoras puras, encontram-se condenadas à deambulação ou à perambulação. São puros videntes, que existem tão somente no intervalo do movimento" (Deleuze, 2007, p. 55).

\section{A signagem onírica na parceria Biörk e Michel Gondry}

Antes de desenvolver a análise do videoclipe Hyperballade (1996), teço rápidas considerações sobre a proposta estética do diretor Michel Gondry, cuja prática audiovisual é marcada pelo hibridismo e por opções formais e técnicas "impuras". Destaco seu assumido trânsito entre o videoclipe, o filme publicitário e o denominado cinema du look - gênero representado por diretores franceses como Luc Besson, JeanJacques Beineix, Jean-Pierre Jeunet e o próprio Gondry.

Além de os comerciais do cineasta serem conhecidos no mundo todo, sua obra é referência como diretor de clipes de artistas tais como: Radiohead, Kylie Minogue, The Vines, Massive Attack, Daft Punk, Foo Fighters, Beck, The Chemical Brothers, The White Stripes, Kanye West, Rolling Stones e Paul McCartney, entre muitos outros.

Em seus filmes Natureza quase humana (2001) Brilho eterno de uma mente sem lembranças (2004), Sonhando acordado (2006) e A espuma dos dias (2013), entre outros, o premiado cineasta cria um universo retrofuturista, com toques do surrealismo e do cubismo, no qual insere aparatos mecânicos inusitados e altas doses de fantasia e inventividade. Seu estilo inconfundível é marcado por planos-sequência, truques diretos na câmera e ousadia na inventividade dos cenários. Por exemplo, os personagens dos filmes atuam em meio a cenários construídos como bricolagens e decorados por inúmeros objetos previamente criados ou improvisados pelo diretor. 
No clipe escolhido para análise e protagonizado pela cantora Björk - também adepta de estratégias inventivas para ilustrar suas canções -, é claramente perceptível a estetização da ambientação cênica, típica do cinéma du look, com a exploração de contrastes nas texturas, da saturação cromática, da iluminação e do impacto visual.

A parceria começou quando Björk convidou-o para dirigir o primeiro single de seu álbum de estreia: Human Behavior (1993). Esse videoclipe tematiza a robotização do ser humano, de modo inventivo e original, porém tudo foi feito da forma mais artesanal possível, usando maquetes, stop motion e diversos truques simples e cujos efeitos líricos tornaram-se as marcas do estilo de Gondry, que dirigiu outros cinco clipes da cantora.

Mesmo estando inserido no circuito das imagens midiáticas estereotipadas, que nosso tempo sabe tão bem explorar, o videoclipe Hyperballad atinge um patamar já definido, em termos de qualidade estética, muito embora conserve as estratégias persuasivas inerentes a um produto da indústria fonográfica. No momento em que utiliza novas ferramentas em sua poética videográfica, modificando a estrutura visual interna, elaborando novas estruturas sígnicas e apropriando-se de outras artes, Gondry cria uma signagem híbrida e inovadora, muito próxima da videoarte, em termos de processos e de efeitos estéticos. Assinalo que Arlindo Machado considera produtivo o fato de alguns diretores de videoclipes levarem "[...] às últimas consequências o hibridismo fundamental do clipe, evitando, dessa maneira, que as imagens figurativas e formas rítmico-abstratas sejam percebidas como coisas diferentes"' (Machado, 2000. p. 180).

Pretendo investigar apenas a construção visual e cinética de Hyperballad, portanto meu artigo não contempla a música em si, nem mesmo sua letra. Meu viés é a exploração dos efeitos expressivos conseguidos pelo diretor, na narrativa audiovisual que explora criativamente o tema onírico - um viés ficcional no qual o absurdo, o fantasmagórico ou o simplesmente estranho convivem sem maiores problemas. Segundo Deleuze, 
[...] se a banalidade cotidiana tem tanta importância, é porque, submetida a esquemas sensório-motores automáticos e já construídos, ela é ainda mais capaz, à menor perturbação do equilíbrio entre a excitação e a resposta [...], de escapar subitamente às leis desse esquematismo e de se revelar a si mesma numa nudez, crueza e brutalidade visuais e sonoras que a tornam insuperável, dando-lhe o aspecto de sonho ou de pesadelo."

(Deleuze, 2007, p. 12)

No videoclipe analisado, tudo se passa como num sonho, porque a narrativa desenvolve-se em torno do desdobramento da imagem da cantora durante o sono, graças à computação gráfica. Por força da disjunção onírica entre o imaginário e os processos racionais, a imagem sonhada mergulha verticalmente e a queda de seu corpo corresponde à dúvida expressa nos versos "I imagine what my body would sound likel Slamming against those rocks/And when it lands, will my eyes be closed or open?"3

Trata-se de uma pergunta sem resposta. Fica a incógnita entre o sonhado e o vivido. Tal ambiguidade é reforçada pelo refrão: "I go thorugh all this before you wake up/ So, I can feel happier to be safe up here with you". ${ }^{4}$

As imagens na tela podem, até mesmo, não aludir à letra e à música da canção porque o que importa são as sugestões, ao invés de explicitações ou obviedades. É o que se percebe nas cenas instáveis e nas fulgurações ininterruptas que compõem a narrativa onírica do clipe, bem ao estilo do diretor Gondry que sempre explora uma oscilação entre estados conscientes e inconscientes, em cenários não naturalistas e ostensivamente artificiais. A obra retoma o tema da convivência instintiva com um mundo complexo de imagens arquetípicas e que conserva, ainda hoje, suas características impactantes, principalmente nos sonhos. O efeito é similar ao descrito 
por Gaston Bachelard, que problematiza nosso conhecimento sobre o espaço onírico e conclui que sobre tais problemas possuímos pouca luz, porque não nos restam senão fragmentos da vida noturna, quando chega o dia.

Esses pedaços de sonho, esses fragmentos do espaço onírico nós os justapomos depois nos quadros geométricos do espaço claro. Fazemos, assim, do sonho uma anatomia com peças mortas. [...] Das transformações oníricas retemos somente as estações. E, no entanto, são as transformações que fazem do espaço onírico o lugar mesmo dos movimentos imaginados."

(Bachelard, 1985, p. 159)

Considero que essa geometria insólita, com "peças mortas", é um dos elementos fulcrais da concepção visual do clipe Hyperballad; sendo que tais formas geométricas se fazem presentes desde o início, no perfil montanhoso e escuro, estando também enfatizadas nas torres triangulares iluminadas e azuis, entre as quais, o corpo sonhado, desvinculado do corpo sonhante, transita aleatoriamente, antes de se lançar no abismo. As formas triangulares são reiteradas no papel amassado que serve de fundo à queda e retornam, ciclicamente ao cenário do sonho, até o final.

No início, uma paisagem noturna, com silhuetas montanhosas escuras, apresenta nuvens azuladas que passam da direita para a esquerda. Identifico nelas as configurações sígnicas que, segundo Peirce pertencem à categoria do firstness: ideias de acaso, indeterminação, originalidade, potencialidade, presentidade, qualidade do processo. 


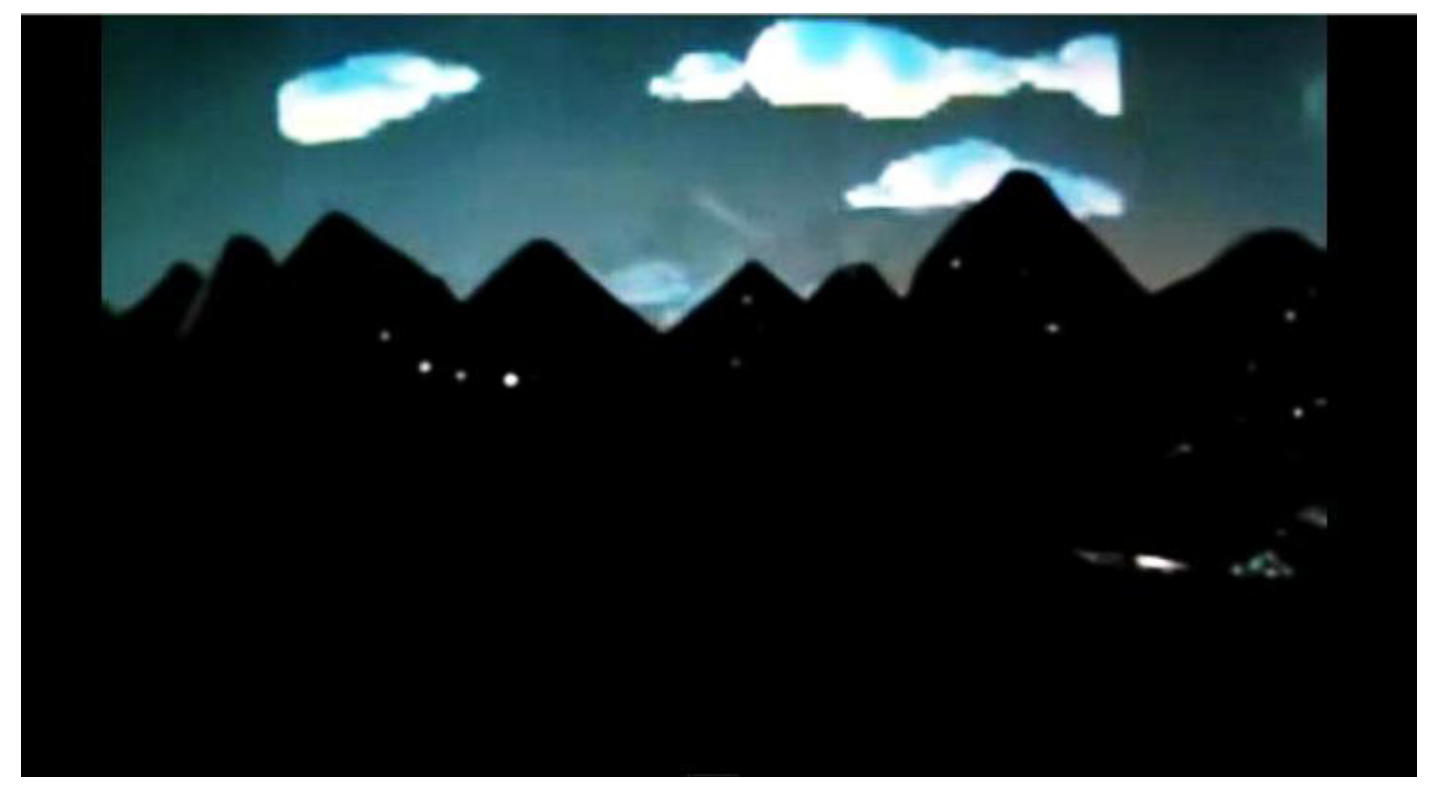

Figura 1 - Frame inicial do videoclipe Hyperballad (1996) dirigido por Michel Gondry ${ }^{5}$ (Imagem captada pela autora, diretamente do videoclipe Hyperballad. Direção Michel Gondry, 1996. Disponível em: <www.youtube.com/watch?v=6CSiU0i_IFA>. Acesso em: 11 a 15 jan. 2014)

O tempo todo, a câmera procura enfatizar a indiscernibilidade entre o subjetivo e o objetivo, o real e o imaginário, assumindo uma nova concepção dos quadros e dos reenquadramentos - como também é frequente nas obras do diretor, com a opção pelos planos fechados. Os agenciamentos sígnicos percebidos correspondem à noção deleuziana da ruptura dos vínculos sensório-motores, ou seja, uma ligação direta a uma imagem tempo que sub-ordena o movimento, sob a forma de cronossigno. 


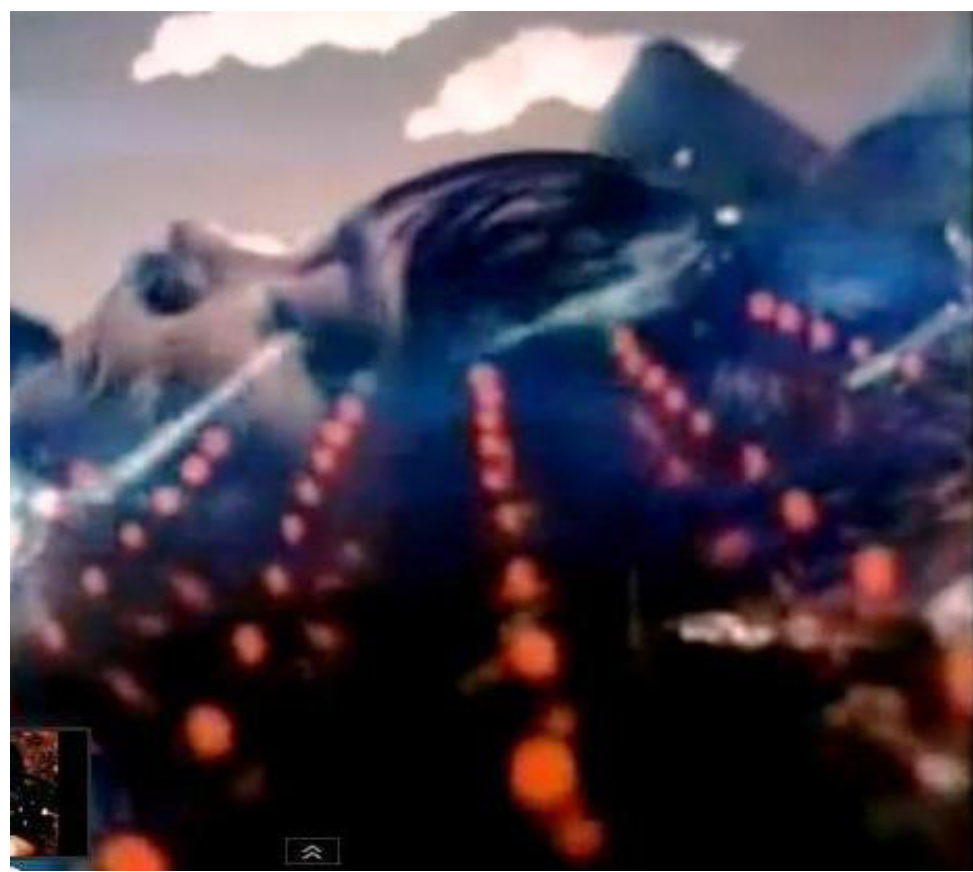

Figura 2 - Frame do videoclipe: cintilações coloridas.

Aos poucos, um efeito de fusão permite perceber, em primeiro plano, o perfil de uma jovem adormecida com a cabeça envolta por cintilações coloridas, com destaque para o vermelho - tonalidade repleta de simbolismos. Assim é que o espaço do sonho rende-se à geometria e à dinâmica do envolvimento, com seus opsignos em ação. 

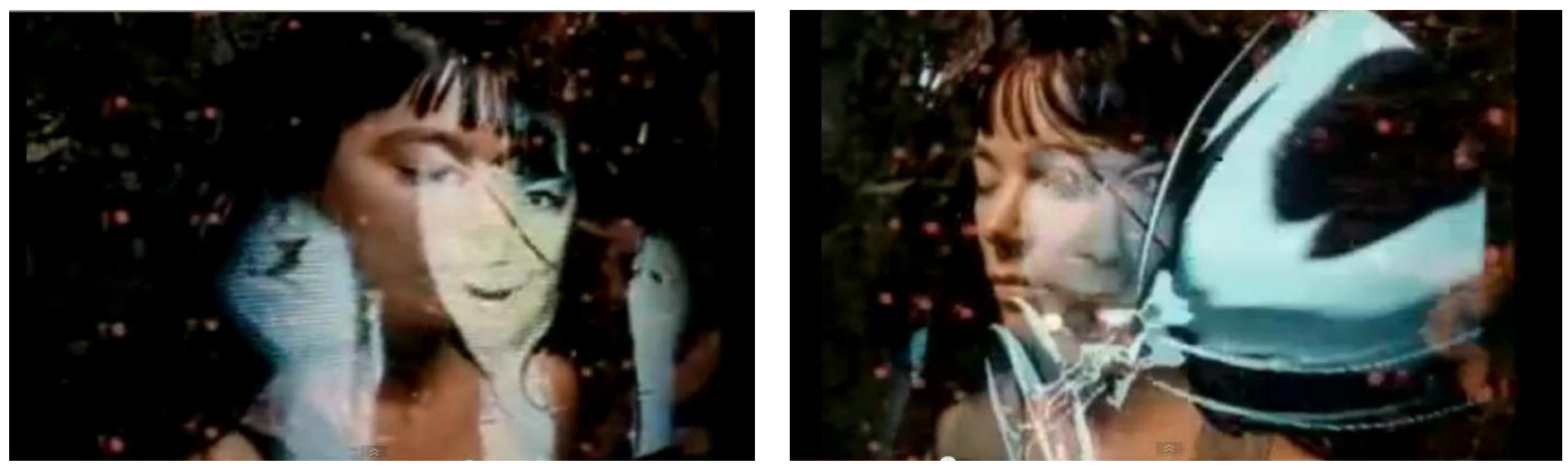

Figura 3 - Frame do videoclipe: Desdobramentos e Fusões.

Figura 4 - Frame do videoclipe: Palimpsestos.

Graças aos recursos técnicos, o rosto sai de si mesmo, num jogo de duplicações e superposições. O EU da protagonista se desdobra no sonho, por força da disjunção onírica entre o imaginário e os processos racionais. A imagem sonhada canta e nuances cromáticas estabelecem os limites entre a sonhadora (cores quentes) e a imagem sonhada (cores frias), sendo ambas perpassadas por objetos translúcidos lançados em sua direção. Identifico o procedimento visualizado na tela com a operação poética de abrir mundos dentro do mundo - que é desdobrado e transformado esteticamente devido à força de práticas desviantes -, como é frequente na pintura moderna. Entendo que o pressuposto kandinskiano da existência de uma energia, proveniente das tensões ocorridas no interior dos elementos da obra pictórica, torna-se válido, também, para os produtos audiovisuais similares ao videoclipe analisado. De acordo com o pintor, 
[...] exteriormente - cada forma é um elemento; interiormente - não é a forma em si, mas a tensão interior que nela vive que constitui um elemento. Desse modo, não são as formas exteriores que materializam o conteúdo da obra pictórica, mas sim as forças que vivem nestas formas. Forças, neste caso, consideradas como tensões."

(Kandinski, 1997, p. 37)

Deleuze costuma relacionar à pintura várias instâncias das imagens fílmicas por ele analisadas. Dir-se-ia que os múltiplos significados dos processos intersemióticos de caráter estético resultam do confronto entre os sistemas sígnicos postos em jogo, por força das tensões entre os elementos.

Como artífice de sonhos e pesadelos, Gondry, em seus filmes e videoclipes, deixa clara sua obsessão por estados alterados de consciência e costuma optar pela técnica do stop motion, explicitando-a para que se altere a percepção espacial dos objetos. A mesma proposta é conferida ao uso da animação, como nas imagens da queda da protagonista, no vídeo analisado. Enfatizo que é uma técnica propositalmente artesanal, cujo efeito consiste em imagens deliberadamente desfocadas, que têm como fundo um cenário similar a papel amassado e que demonstram a ênfase no artificial.

Percebo que tais cenas são típicas do estilo de Gondry, que costuma fazer uso da precariedade do cenário e uma aparentemente descuidada execução dos objetos de cena. Tais estratégias seriam como uma espécie de "defeito visual" - que lhe atribuem certos críticos -, mas que se estatuem como marcas estilísticas de sua produção audiovisual. Confirma-se minha hipótese que o videoclipe de Gondry conserva reverberações do cinéma $d u$ look, cujos diretores dedicavam-se à inovação de uma linguagem cinematográfica pós-moderna, derivada da cultura popular e influenciada pelos avanços das tecnologias. 


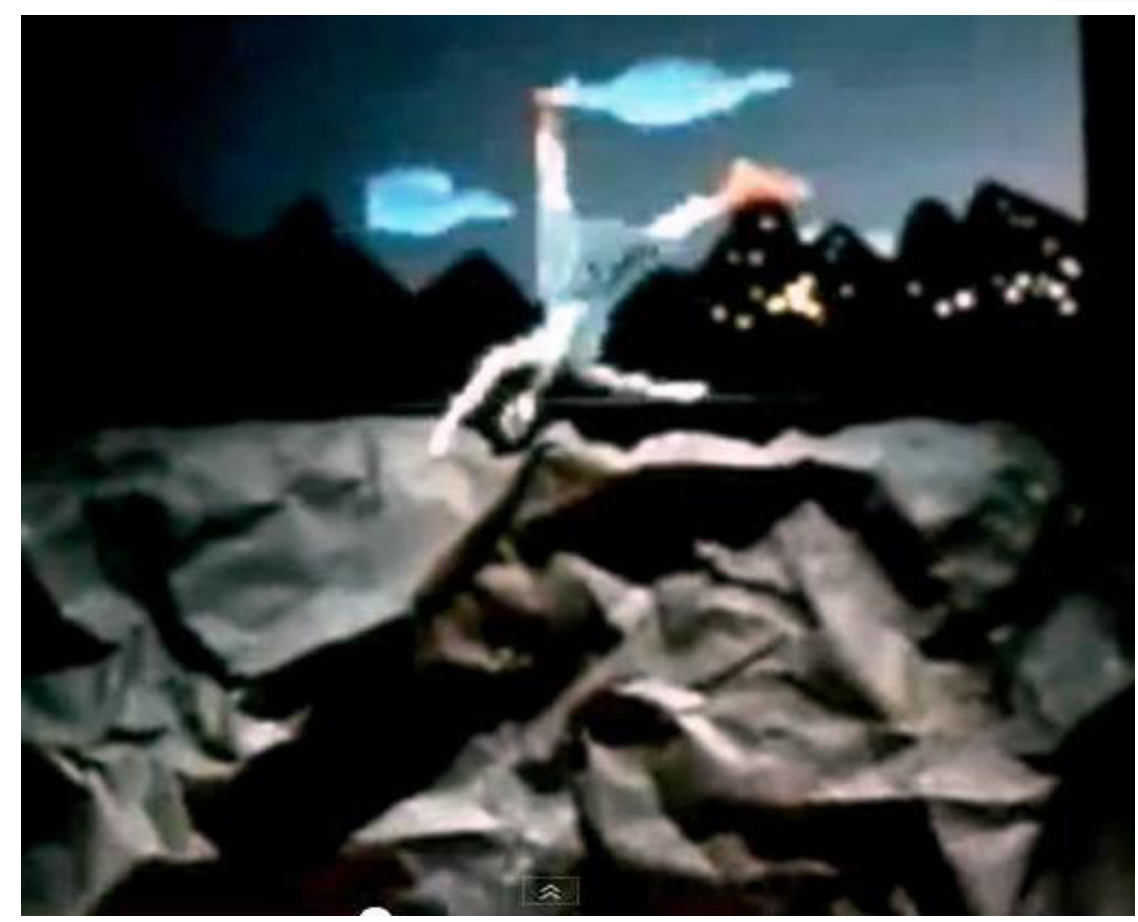

Figura 5 - Frame do videoclipe: A queda.

O antinaturalismo das cenas coaduna-se ao conceito do tempo no gênero videoclipe, expresso por Arlindo Machado, quando afirma que as imagens não precisam "durar" o tempo necessário para serem reconhecidas como seres do mundo material. O autor assinala que, além da atitude de inconformismo com relação aos cânones, 
[...] o videoclipe busca também algo assim como uma nova visualidade, mais gráfica e rítmica do que fotográfica. [...] as imagens do clipe têm sido tão esmagadoramente contaminadas pelas suas trilhas musicais, que acaba sendo inevitável a sua conversão em música, isto é, numa calculada, rítmica e energética evolução de formas no tempo."

(Machado, 2000, p. 178)

Na narrativa do clipe, como "evolução de formas no tempo", a grande maioria dos efeitos visuais foi produzida de forma mecânica e artesanal. Tal opção pode ser verificada no cenário e nos objetos de cena, aparentemente "mal acabados".

$\mathrm{Na}$ aceleração da queda rompem-se os efeitos gravitacionais e, numa espécie de indução arquetipal, a figura humana paira, plana e gira em todas as direções, ficando implícita a experiência ambígua entre curiosidade e medo, dor e êxtase, característica do ato de sonhar. Acentua-se a sensação angustiante do tempo e da vertigem, que se traduz por reações sensório-motoras impactantes e incontroláveis como explica Deleuze: “[...] entre a realidade do meio e da ação, não é mais um prolongamento motor que se estabelece, é antes, uma relação onírica, por intermédio dos órgãos dos sentidos, libertos" (Deleuze, 2007, p. 13).

Da perspectiva das formas simbólicas, o antropólogo Durand entende a vertigem, muito presente nos sonhos, como "imagem inibidora de toda a ascensão, um bloqueamento psíquico e moral que se traduz por fenômenos psicofisiológicos violentos. A vertigem é um relembrar brutal da nossa humana e presente condição terrestre" (Durand, 2002, p. 113). 
A descida/queda da protagonista do clipe termina no encontro com o solo, no qual a jovem aparentemente mergulha e emerge, em seguida. Mas não se trata de um terreno amistoso e seguro, pois tudo oscila e gira, enfatizando o desequilíbrio. Observam-se novas fusões e superposições, fragmentações, deslocamentos topográficos ou interações entre imagens e camadas que apontam para os processos cubistas de rejeição às técnicas tradicionais de perspectiva, bem como à negação da ideia de arte como imitação da natureza.

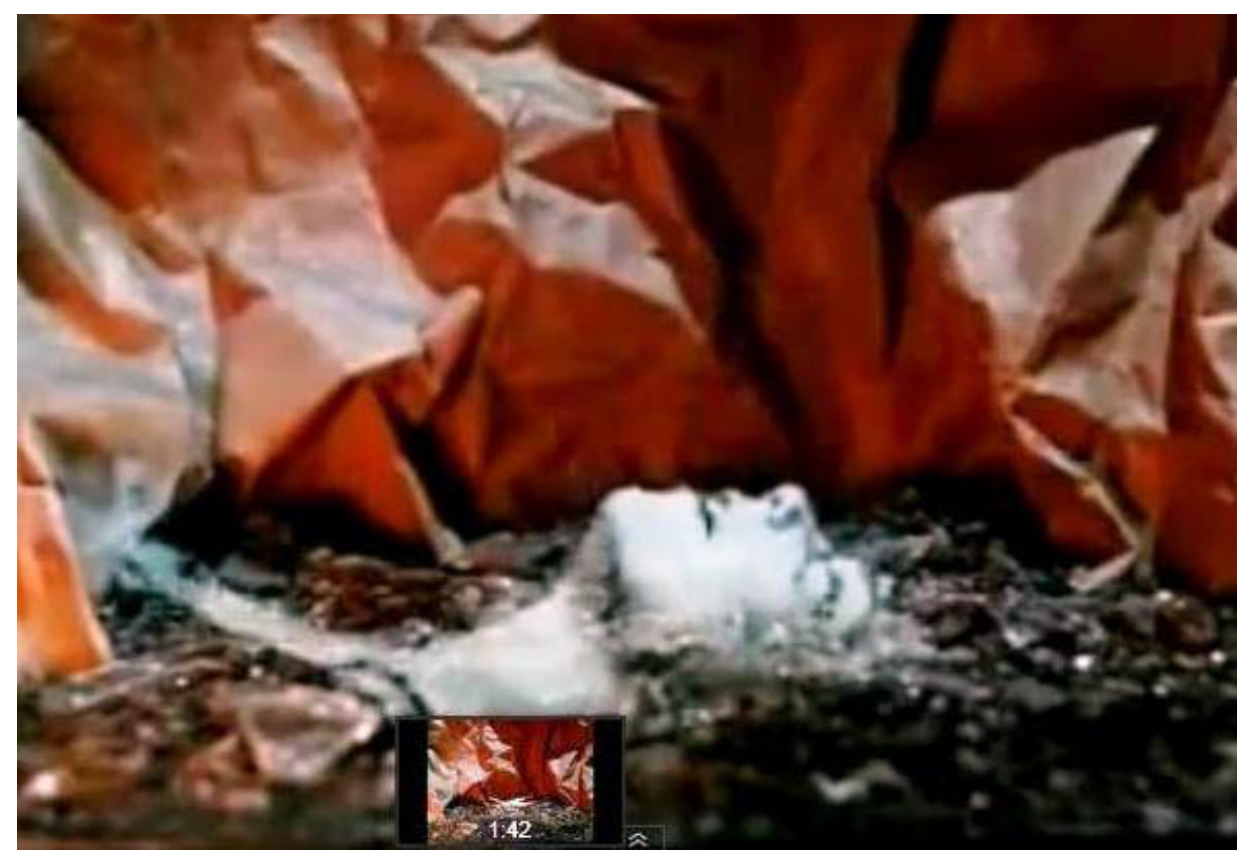

Figura 6 - Frame do videoclipe: Deslocamentos imponderáveis. 
Observo que, nesse sentido, Gondry utiliza os recursos expressivos próprios do chamado "efeito vídeo" para reproduzir a experiência intensificadora e inefável do sonho, na narrativa videoclípica, marcada por formas atemporais e pela simultaneidade de planos.

Volta-se ao primeiro plano do rosto adormecido, que permite a compreensão do objetivo desta obra audiovisual: o de criar, por meio da decomposição e superposição de planos, uma imagem conceitual do sonhado, além da representação. Esse é justamente o tipo de efeito audiovisual referido por Deleuze, no qual o vidente substitui o actante. Diz ele:

De repente, as situações já não se prolongam em ação ou reação, como exigia a imagem-movimento. São puras situações óticas e sonoras, nas quais a personagem não sabe como responder, espaços desativados nos quais ela deixa de sentir e de agir, para partir para a fuga, a perambulação, o vaivém, vagamente indiferente ao que lhe acontece, indecisa sobre o que é preciso fazer."

(Deleuze, 2007, p. 323)

Creio que as assertivas do filósofo dedicado ao cinema ajustam-se ao que ocorre no videoclipe analisado: em estado de sono agitado e sonho, a personagem foge - ao saltar no abismo - e, perambula, entre idas e vindas, impossibilitada de agir ou reagir.

Durante todo o videoclipe, o sono da protagonista é agitado, apresentando superposições das imagens sonhadas, como mudanças desniveladas e céleres, com a inserção de novas quedas. Considero que os cortes metonímicos e sua remontagem 
como palimpsestos devem ser considerados como fatos plásticos independentes e que, em determinados momentos, abstraem a aparência imediata da jovem. Semioticamente, seriam signos icônicos, numa proposição tão monádica que se aproximaria da talidade peirciana como, explicada por Santaella. "São efeitos de forma, qualidade de linhas e superfície, combinações de massas e volumes, tanto quanto possível libertos de esquemas, diagramas ou de composições" (Santaella, 2001, p. 212).

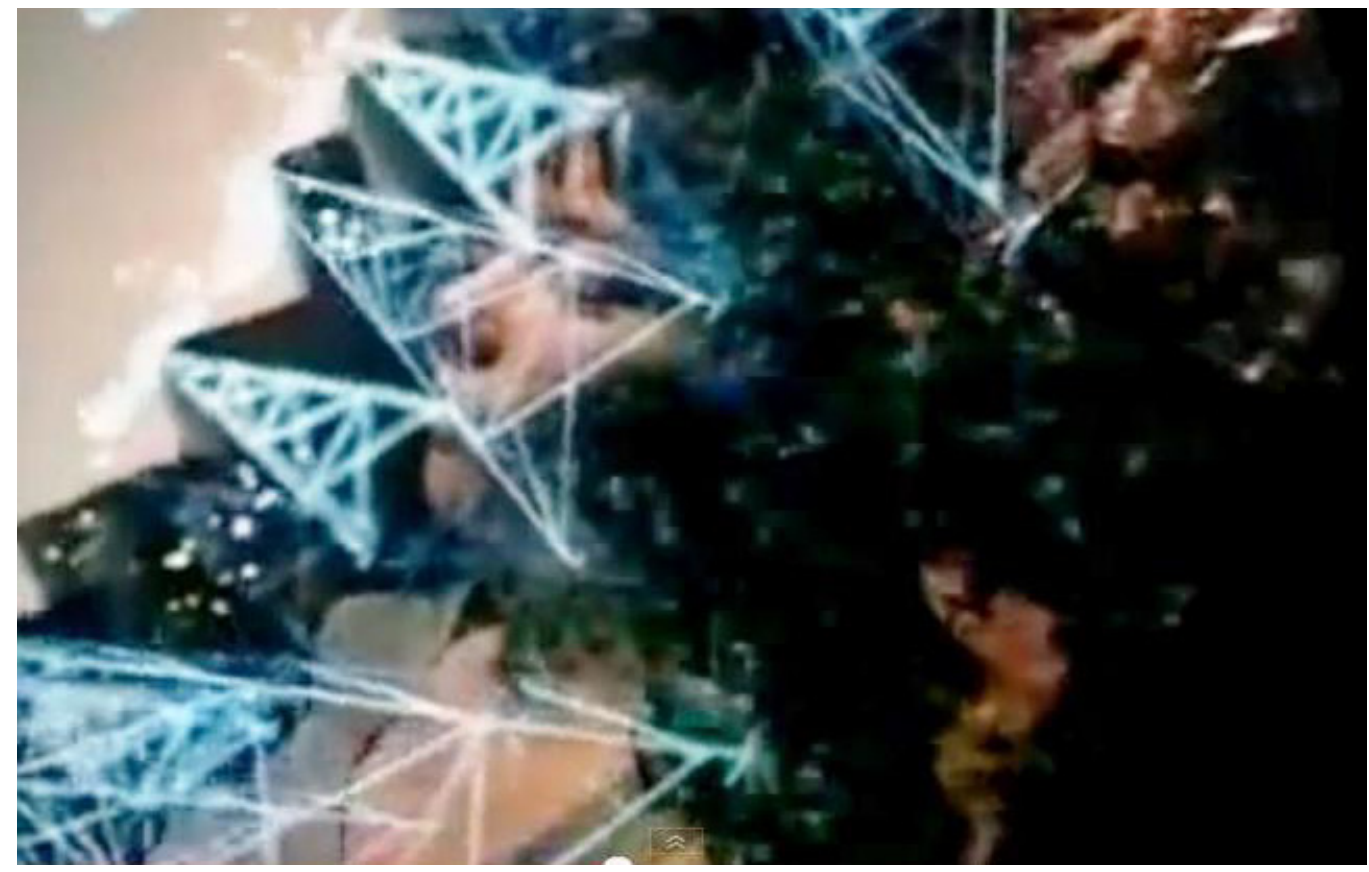

Figura 7 - Frame do videoclipe: proposição monádica. 
As reiterações do desdobramento onírico da figura humana e das imagens da queda são ícones impregnados de conotações ligadas ao medo primitivo de cair e que podem ser associados ao pensamento de Bachelard sobre a ubiquidade dos eventos distópicos e sincrônicos.

Para imaginar a vertigem, cumpre reintegrá-la à filosofia do instante, surpreendê-la em sua diferença total, quando todo o nosso ser desfalece. É um devir fulminante. [...] A queda deve ter todos os sentidos ao mesmo tempo: deve ser simultaneamente metáfora e realidade."

(Bachelard, 1990, p. 93)

O autor considera "a imaginação da queda como uma espécie de doença da imaginação da subida, como a nostalgia inexpiável da altura" (Bachelard, 1900, p. 95).

Próximo ao final do videoclipe, por intermédio de múltiplas interpenetrações possíveis, além de processos de interferência, mistura e incorporação, a imagem em primeiro plano do rosto adormecido passa a ser é inserida em um cenário urbano noturno, iluminado com cores vivas e cujo céu sugere o crepúsculo. Aliada às estratégias técnicas, a iluminação confere cores diversas às cenas e permite que o tema onírico tornese um pretexto para a obtenção de efeitos singulares e precisos efeitos compositivos.

De repente, o cenário transforma-se em edifícios feericamente iluminados, em tons de azul - o que me lembra o pensamento de Peixoto, em seu estudo sobre cinema e pintura, no qual considera que a contemporaneidade efetua um resgate da experiência da luz, tanto no cinema quanto na fotografia. "O aqui e agora de sua presença na imagem. A demarcação de um lugar e tempo através da sua ocorrência. Um advento: anunciação. O acontecimento da luz, diferente da reprodutibilidade técnica da luz" (Peixoto, 1996, p. 291). 
Na tela, gradativamente, a figura humana se esvai e restam apenas trilhas compostas de pontos vermelhos brilhantes que se encaminham para o contorno montanhoso e escuro do início, onde passeiam as nuvens azuis. As linhas visualizadas na tela, como pontos de fuga, apontam para um espaço no limiar do sonhado, o que me leva novamente ao pensamento de Bachelard: “O espaço onírico próximo do despertar possui feixes de retas finas; a mão que espera o despertar é um tufo vivo, um tufo de músculos, desejos, projetos" (Bachelard, 1985, p. 162).

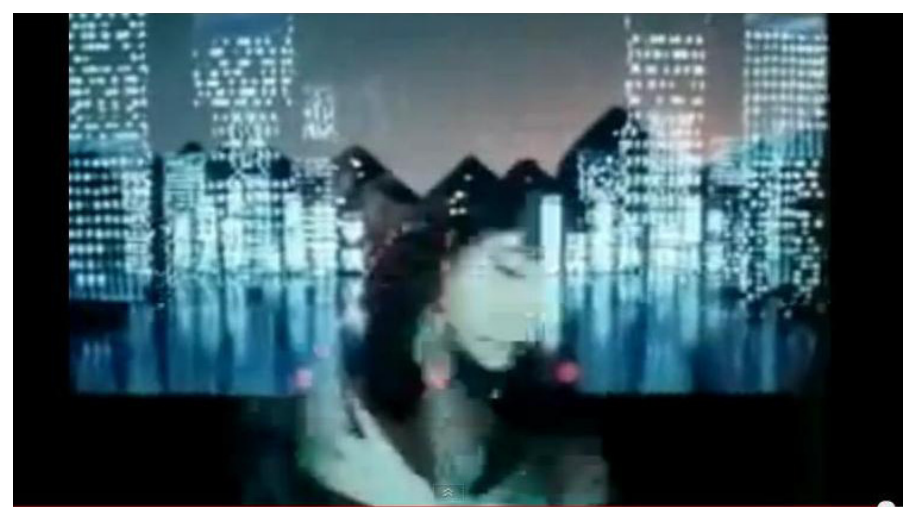

Figura 8 - Frame do videoclipe: O acontecimento da luz.

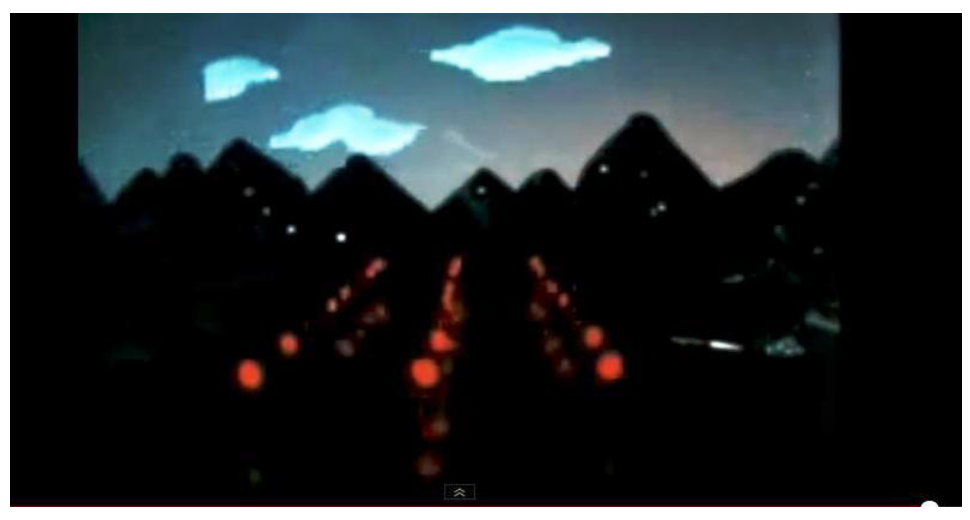

Figura 9 - Frame do videoclipe: O eterno retorno.

Fecha-se o ciclo. A noção mítica do eterno retorno é sugerida com as imagens finais similares às do início, com a trilha luminosa em direção ao que Deleuze denomina de espaço qualquer. A chave de acesso a tal espaço são os agenciamentos sígnicos intersticiais, plenos de vazio e que se aproximam da "zeroidade". 
[...] o ponto de partida era apenas em aparência uma situação sensóriomotora: mais aprofundadamente, era uma situação ótica e sonora pura que já havia perdido seu prolongamento motor, era pura descrição que já substituíra seu objeto, um puro e simples cenário. Então, o movimento de mundo responde diretamente ao apelo dos opsignos e sonsignos (e o 'grau zero' não mais documenta uma ação progressiva, mas a anulação dos vínculos sensório-motores comuns)."

(Deleuze, 2007, p. 79)

Faz-se o silêncio e o clipe termina com as três camadas distintas em cores, formas e texturas, numa alusão a um devir, a um reencadeamento infinito, a partir do vazio, ou das potências do falso.

\section{A potencialidade onírica e o devir infinito}

Nesse entrelugar das poéticas tecnológicas pós-modernas, tudo é percepção, nada é logicamente explicável; pois, mesmo em face da multiplicidade sígnica e da hibridação, inerentes às produções estéticas contemporâneas, a arte continua vinculada a um tipo de vivência suprarracional. Tal experiência perceptiva efetua uma apreensão direta e não mediada do objeto, vivenciado "no aqui" e "no agora", como nos sonhos. Trata-se de uma espécie de enclave na objetividade, que denomino caráter "presentacional" da experiência estética, evidenciado na malha sígnica da configuração audiovisual de Hyperballad. Nela, a pura potencialidade onírica estaria apresentada, não mais representada, como uma forma de acontecimento, em seu devir infinito - uma potência qualitativa identificável à "qualidade do sentimento" ou qualis, própria da primeiridade como entendida na semiótica de Peirce. 
Acredito que, na imponderabilidade da apresentação videoclípica, revela-se adequado o entendimento de Deleuze em relação ao cinema moderno, como tento demonstrar neste artigo, pois, afinal,

Por um lado, a apresentação cinematográfica torna-se uma apresentação direta tempo, conforme relações não-comensuráveis e cortes irracionais. Por outro, essa imagem-tempo põe o pensamento em relação com um impensado, o inevocável, o inexplicável, o indicível, o incomensurável. O fora ou o avesso das imagens substituíram o todo, ao mesmo tempo que o interstício ou o corte substituíram a associação."

(Deleuze, 2007, p. 256)

A análise desenvolvida permite-me afirmar que a concepção tecnoestética da obra dirigida por Michel Gondry vai além da mera divulgação da indústria fonográfica, permitindo perceber que, tanto o vídeo, quanto a fotografia e o cinema se fazem poesia, quando se mostram capazes de interromper a narração, de dissolver o espaço e de suspender o tempo; ou seja, quando revelam a consciência da incapacidade das imagens de darem conta dos eventos e quando a força motriz da translação torna-se expressão do intangível e do inefável.

\section{REFERÊNCIAS}

BACHELARD, Gaston. O direito de sonhar. São Paulo: DIFEL, 1985.

. O ar e os sonhos - ensaio sobre a imaginação do movimento. São Paulo: Martins Fontes, 1990.

COUCHOT, Edmond. A tecnologia na arte, da fotografia à realidade virtual. Porto Alegre: Editora da UFRGS, 2003.

DELEUZE, Gilles. A imagem-tempo. São Paulo: Brasiliense, 2007. 
DERRIDA, Jacques. A escritura e a diferença. São Paulo: Perspectiva, 1971.

DURAND, Gilbert. As estruturas antropológicas do imaginário. São Paulo: Martins Fontes, 2002.

KANDINSKY, Wassily. Ponto e linha sobre plano. São Paulo: Martins Fontes, 1997.

MACHADO, Arlindo. A televisão levada a sério. São Paulo: Editora Senac São Paulo, 2000.

PEIRCE, Charles Sanders. Escritos coligidos. In: Peirce. Frege. São Paulo: Abril Cultural, 1983. p. 4-176.

. Semiótica. São Paulo: Perspectiva, 1999.

PEIXOTO, Nelson Brissac. Cinema e Pintura: a pintura, a fotografia, o cinema e a luz. In: XAVIER, Ismail (Org.). O cinema no século. Rio de Janeiro: Imago, 1996.

PIGNATARI, Décio. Signagem da Televisão. São Paulo: Brasiliense, 1984.

SANTAELLA, Lúcia. Matrizes da linguagem e pensamento. Sonora. Visual. Verbal. São Paulo: Iluminuras, 2001. XAVIER, Ismail. O discurso cinematográfico: a opacidade e a transparência. São Paulo: Paz e Terra, 2008.

\section{NOTAS}

1 Hyperballad. Directed by Michel Gondry. Written by Björk. Published by Universal Music Publishing Ltd ${ }^{\circledR}$ 1996.

2 Cinéma du Look. Movimento do cinema francês, originário dos anos de 1980, no qual o estilo era mais relevante do que a narrativa, com visual característico e ligado à cultura pop do espetáculo. Serviram-lhe de influência: comerciais de televisão, videoclipes, fotografias de moda, filmes de Werner Fassbinder e o novo cinema americano, além de determinadas encenações operísticas.

3 Tradução livre: Eu imagino como meu corpo pode soar/Batendo contra as rochas/E quando ele pousar, estarão meus olhos fechados ou abertos?

4 Tradução livre: Eu vou conseguir tudo isso antes que você acorde/Então eu poderei sentir-me feliz por estar salva aqui com você.

5 Todos os frames do videoclipe foram obtidos pela autora do artigo, diretamente da Internet. Disponível em: <youtubwww.youtube.com/watch?v=6CSiU0j_1FA>. Acesso em: 11 a 15 jan. 2014.

Recebido em: 07 abr. 2014

Aceito em: 04 ago. 2014

Endereço da autora:

Denise Azevedo Duarte Guimarães < denise.guimaraes@utp.br>

Universidade Tuiuti do Paraná

Rua Sydnei Antonio Rangel Santos, 238 - Santo Inácio

82010-330 Curitiba, PR, Brasil 